\title{
Synthesis of Steroidal Indoxyl, and Derivatives from 3-Ketosteroid
}

\author{
F.N. KAMAU \\ 'Department of Pharmaceutical Chemistry, School of Pharmacy, College of Health Sciences, University \\ of Nairobi, P.O. Box 19676-00202, Nairobi, Kenya.
}

\begin{abstract}
$5 \propto-$-Androstan-17 $\beta$-ol-3-one condenses with 2-nitrobenzaldehyde in alkaline conditions to give the steroidal indoxyl $17 \beta$-hydroxy-1-(3'-oxoindan-2'-yliden)-3nor-1,2-secoandrostan-3-oic acid (I) which on refluxing with acetic anhydride affords the lactam 17 $\beta$-acetoxy-3'-aza-4a-homoandrost-1-eno-(3,2-a)-indan-3',4dione (II). Reduction of I with sodium borohydride gives the indole $17 \beta$-hydroxy-1(indol-2'-yl)-3-nor-1, 2-secoandrostan-3-oic acid (III). The results of this synthesis suggest that 3-ketosteroids saturated in ring $A$ react in a similar manner to 17ketosteroids, with 2-nitrobenzaldehyde.
\end{abstract}

Key words: Synthesis, Steroidal Indoxyl, derivatives.

\section{INTRODUCTION}

17-ketosteroids condense with 2-nitrobenzaldehyde in alkaline conditions to give steroidal indoxyls, which in turn can be cyclised to steroidal lactams on refluxing with acetic anhydride. Steroidal indoxyls give a steroidal indole on reduction with sodium borohydride [1$3]$. Such syntheses involving 3-ketosteroids have not been reported previously.

The primary interest was to extend the range of steroid indoxyls, lactams and indoles that can be synthesized, for pharmacological evaluation. In the present paper the synthesis of a steroidal indoxyl, lactam and indole from a 3-ketosteroid (Figure 1) is reported.

\section{MATERIALS AND METHODS}

\section{Reagents}

$17 \beta$-Hydroxy-5 $\alpha$-adrostan-3-one was purchased from Sigma Chemical Company. 2Nitrobenzaldehyde was obtained from Aldrich Chemical Company. The rest of the reagents and solvents were obtained from B.D.H and used without further purification. Elemental analyses were performed by Galbraith Laboratories Inc. Sycmore, Knoxville, TN., USA. Infrared spectra were scanned as nujol mulls on a PE $727 \mathrm{~B}$ spectrophotometer. UV spectra were recorded in methanol on a Pye Unicam SP 8000 spectrophotometer. NMR spectra were run in $\mathrm{C}_{5} \mathrm{D}_{5} \mathrm{~N}$ except for compound III ( ${ }^{1} \mathrm{H}-\mathrm{NMR}$ in
$\mathrm{CDCl}_{3}$ ) on a HEOL Gx 270 FTNMR fitted with 5 $\mathrm{mm} \mathrm{C} / \mathrm{H}$ dual probe. MS spectra were recorded on a $70 \mathrm{eV}$ EIMS spectrometer. The purity of the compounds was confirmed by TLC using $\mathrm{CHCl}_{3}$ : $\mathrm{MeOH}$ 9:1 on POLYGRAM SIL G/UV 254 silicagel precoated plastic plates.

\section{Synthesis}

17 $\beta$-Hydroxy-1-(3'-oxoindan-2'-ylidene)-3-nor-1, 2-secoandrostan-3-oic acid (I): To a solution of $17 \beta$-hydroxy-5 $\propto$-androstan-3-one $(1.0 \mathrm{~g}, 3.45$ $\mathrm{mmol})$ in $\mathrm{MeOH}(50 \mathrm{ml})$ was added aqueous $\mathrm{KOH}$ $(1.0 \mathrm{~g}$ in $1 \mathrm{ml})$ followed by a $\mathrm{MeOH}$ solution of 2 nitrobenzaldehyde $(0.75 \mathrm{~g}, 5 \mathrm{mmol}$ in $10 \mathrm{ml})$. After $24 \mathrm{~h}$ at room temperature in the dark, the solution was concentrated under vacuum and acidified with diluted $\mathrm{HCl}$. The yellow precipitate was collected by filtration, washed with water, dried and recrystallised from methanol - water to give $I(0.72 \mathrm{~g}, 63.0 \%)$ as yellow crystals, m.p. 228-229 ${ }^{\circ} \mathrm{C}$; UV $\lambda \max 238,259,275$ (sh), 300 (sh) $448 \mathrm{~nm}$; IR $\gamma \max 3400(\mathrm{O}-\mathrm{H}), 3350(\mathrm{~N}-\mathrm{H})$, $2700-2300(\mathrm{COOH}) 1700(\mathrm{C}=\mathrm{O}$ of $\mathrm{COOH}) 1680$, $1640(\propto, \beta$-unsat $C=0$ ). $1620 \mathrm{~cm}-1:$ MS m/z 423 $(\mathrm{M}+, 100), 405$ (34), $220(40,173$ (46), $146(85)$. Anal: Calculated for $\mathrm{C}_{26} \mathrm{H}_{33} \mathrm{O}_{4} \mathrm{~N} \mathrm{C} 73.76 \mathrm{H} .7 .80$, found C. $73.78 \mathrm{H} 7.97$.

17 $\beta$-Acetoxy-3-aza-4a-homoandrost-1-eno-(3,2-a) indan- 3',4-dione (II): The indoxyl (I) in $\mathrm{Ac}_{2} \mathrm{O}$ $(2 \mathrm{~g}$ in $60 \mathrm{ml})$ was refluxed for $12 \mathrm{~h}$ and poured into ice-water to give a pink precipitate. Two recrystallisations from EtOH- $\mathrm{H}_{2} \mathrm{O}$ gave II $(1.6 \mathrm{~g}$,

* Author to whom the correspondence may be addressed. 


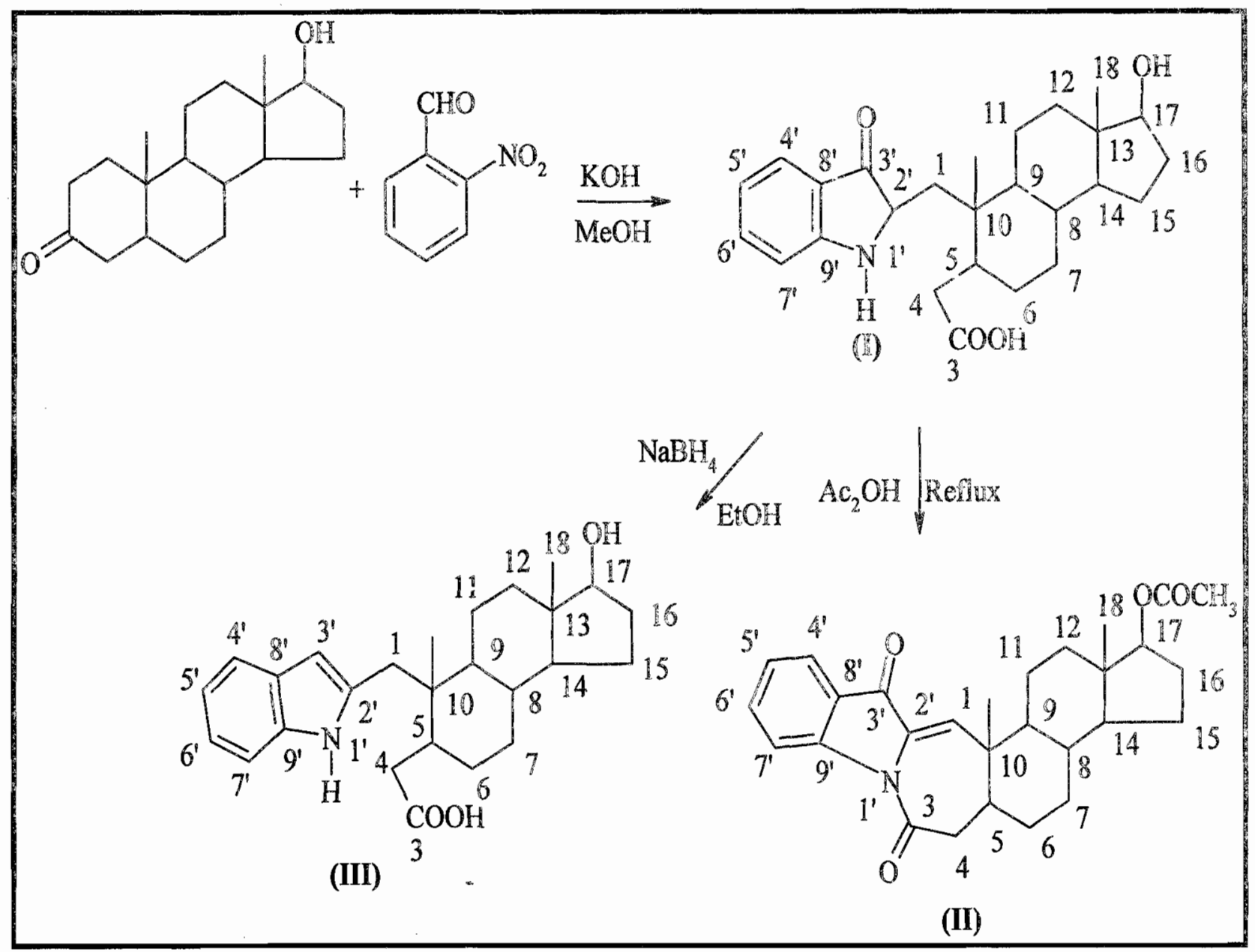

\section{Figure 1: Scheme of Synthesis}

$75.7 \%$ ) as light pink crystals, m.p. $193-195^{\circ} \mathrm{C}$; UV $\lambda \max 212,244,257$ (sh), 275 (sh), 358 (sh), $364,396(\mathrm{sh}) \mathrm{nm} ; 1 \mathrm{R} \gamma \max 1750(\mathrm{C}=\mathrm{O}$ of acetate $)$ $1700(\mathrm{C}=\mathrm{O}$ of lactam $) 1660,1620(\alpha, \beta-$ unsaturated $\mathrm{C}=\mathrm{O}) \mathrm{cm}^{-1}$; MS m/z $447\left(\mathrm{M}^{+}, 100\right)$, 159 (72) 146 (24). Anal: Calculated for $\mathrm{C}_{28} \mathrm{H}_{33} \mathrm{O}_{4} \mathrm{~N} \mathrm{C} 75.15 \mathrm{H} 7.38$, found C 74.91 H 7.51.

\section{7 $\beta$-Hydroxy-1-(indol-2'-yl)-3-nor-1,2-secoandro-} stan -3-oic acid (III): The indoxyl (I) in EtOH $(3.0 \mathrm{~g}$ in $300 \mathrm{ml})$ was reduced by gradual addition of $\mathrm{NaBH}_{4}(12 \mathrm{~g})$. The mixture was concentrated under reduced pressure and acidified by dropwise addition of dilute $\mathrm{HCl}$ with stirring. The white precipitate was washed with water, dried and recrystallised from EtOH $-\mathrm{H}_{2} \mathrm{O}$ to give III as white amorphous crystals, m.p. $153-155^{\circ} \mathrm{C} ; \lambda \max$
212. (sh), 212, 275, $290 \mathrm{~nm}$; IR $\gamma \max 3425(\mathrm{OH}$ NH) $2700-2300(\mathrm{COOH}) 1710(\mathrm{C}=\mathrm{O}) \mathrm{cm}^{-1}$; MS $\mathrm{m} / \mathrm{z} 409\left(\mathrm{M}^{+}, 11\right) 144(60) 131$ (100) $130(40)$.

\section{RESULTS AND DISCUSSION}

Compound I, obtained as yellow crystalline needles from methanol-water by reaction between $5 \circ$-androstan-17ß-ol-3-one, which is a 3ketosteroid, and 2-nitrobenzaldehyde in the presence of potassium hydroxide, shows in its UV spectrum features of a highly conjugated system. The IR spectrum shows peaks at 3350 and 1620 $\mathrm{cm}^{-1}$ which are characteristic of indoxyls [4]. Its ${ }^{1} \mathrm{H}-\mathrm{NMR}$, shows broad $\mathrm{D}_{2} \mathrm{O}$ exchangeable proton signals at $9.86 \mathrm{ppm}(\mathrm{N}-\mathrm{H})$ and $2.56 \mathrm{ppm}(\mathrm{O}-\mathrm{H})$, in addition to four aromatic protons, together with a singlet signal at $6.28 \mathrm{ppm}(\mathrm{I}-\mathrm{H})$ (Table 1$),{ }^{13} \mathrm{C}$ - 
NMR spectrum for compound I shows peaks due to two carbonyl carbons at $186.64 \mathrm{ppm}$ and $175.90 \mathrm{ppm}$ for the indoxyl carbonyl and carboxyl groups respectively (Table 2). An EI mass spectrum of compound I shows the molecular ion peak at $\mathrm{m} / \mathrm{z} 423$ which is the base peak. Elemental analysis provides further evidence for the structure of this compound.

The mechanism of formation of steroidal indoxyls from 17-ketosteroids has previously been described [1] and has analogy in the synthesis of indigo from acetone and 2-nitrobenzaldehyde 15 it proceeds via aldol-like intermediate formed by the attack of the aldehyde group of 2nitrobenzaldehyde on the 16-methylene group of 17-ketosteroids. The ortho nitro group of the aldehyde induces the aldol intermediate to react preferentially by an intramolecular carbanion attack on the nitro group to give the indoxyl. With 3-ketosteroids an attack at the 2-rather than 4position, can be expected and such attack is hindered by a 2 -methyl substituent [ 6$]$.

Table 1: Proton NMR Chemical Shifts for Compounds I, II and III

\begin{tabular}{ccccc}
\hline PROTON & I & \multicolumn{1}{c}{ I } & \multicolumn{1}{c}{} \\
\hline 1 & $6.28 \mathrm{~s}$ & $6.75 \mathrm{~s}$ & - \\
3 & $2.56 \mathrm{~s}$ & - & - \\
5 & - & $2.90 \mathrm{dd}$ & $3.20 \mathrm{~d}$ \\
9 & - & $2.44 \mathrm{~d}$ & - \\
17 & $3.87 \mathrm{t}$ & $4.56 \mathrm{~m}$ & $3.77 \mathrm{t}$ \\
18 & $0.97 \mathrm{~s}$ & $0.81 \mathrm{~s}$ & $0.91 \mathrm{~s}$ \\
19 & $1.33 \mathrm{~s}$ & $1.17 \mathrm{~s}$ & $0.99 \mathrm{~s}$ \\
$1^{\prime}$ & $9.865, \mathrm{br}$ & - & - \\
$3^{\prime}$ & - & - & $6.78 \mathrm{~s}$ \\
$4^{\prime}$ & $7.90 \mathrm{~d}$ & $8.50 \mathrm{~d}$ & $7.65 \mathrm{dd}$ \\
$5^{\prime}$ & $7.35 \mathrm{t}$ & $7.83 \mathrm{dd}$ & $7.20 \mathrm{~d}$ \\
$6^{\prime}$ & $6.86 \mathrm{t}$ & $7.65 \mathrm{~m}$ & $7.18 \mathrm{~s}$ \\
$7^{\prime}$ & $6.94 \mathrm{~d}$ & $7.26 \mathrm{~m}$ & $7.81 \mathrm{dd}$ \\
$2^{\prime}$ & - & $2.05 \mathrm{~s}$ & - \\
\hline
\end{tabular}

$\mathrm{s}=$ singlet, $\mathrm{d}=$ doublet $\mathrm{t}=$ triplet, $\mathrm{m}=$ multiplet, $\mathrm{b}=$ broad

Table 2. ${ }^{13} \mathrm{C}$ NMR Chemical Shifts for Compounds I, II and III

\begin{tabular}{cccc}
\hline Carbon & I & II & III \\
\hline 1 & 136.32 & 136.32 & 35.17 \\
2 & - & - & - \\
3 & 175.90 & 171.92 & 177.77 \\
4 & 38.44 & 42.03 & 37.33 \\
5 & 40.11 & 41.19 & 40.81 \\
6 & 23.66 & 29.37 & 28.85 \\
7 & 30.88 & 31.21 & 31.01 \\
8 & 34.94 & 34.49 & 35.89 \\
9 & 52.53 & 52.06 & 51.04 \\
10 & 43.42 & 42.16 & 40.51 \\
11 & 27.32 & 21.67 & 22.19 \\
12 & 37.47 & 36.62 & 37.45 \\
13 & 43.69 & 42.43 & 43.26 \\
\hline
\end{tabular}


Table 2: Cont'd

\begin{tabular}{cccc}
\hline Carbon & I & II & III \\
\hline 14 & 31.17 & 50.48 & 48.13 \\
15 & 23.84 & 23.57 & 23.64 \\
16 & 30.88 & 27.54 & 30.92 \\
17 & 81.19 & 82.53 & 81.08 \\
18 & 11.84 & 12.60 & 11.93 \\
19 & 14.84 & 14.41 & 15.91 \\
$2^{\prime}$ & 155.38 & 149.31 & 137.02 \\
$3^{\prime}$ & 186.64 & 184.45 & 102.26 \\
$4^{\prime}$ & 119.41 & 118.63 & 119.56 \\
$5^{\prime}$ & 124.87 & 124.12 & 120.94 \\
$6^{\prime}$ & 124.36 & 124.79 & 120.94 \\
$7^{\prime}$ & 112.43 & 129.58 & 111.27 \\
$8^{\prime}$ & 122.75 & 123.76 & 129.70 \\
$9^{\prime}$ & 155.38 & 130.80 & 136.75 \\
20 & - & 171.20 & - \\
21 & - & 21.18 & - \\
\hline
\end{tabular}

The structure of compound $\mathbf{I}$ is also indirectly confirmed because on refluxing with acetic anhydride, it gives the 7-membered ring lactam (II). As expected, the 17-hydroxyl group is acetylated during the reaction. Cyclisation of steroidal indoxyls derived from 17-ketosteroids under similar conditions gives 5-membered ring lactams where the $\alpha, \beta$-unsaturated carbonyl group is at the same time converted to the enol acetate [I]. The assignment of the structure of compound II was suggested by the absence of $\mathrm{N}-\mathrm{H}$ or $\mathrm{O}-\mathrm{H}$ peaks in its IR and ${ }^{1} \mathrm{H}$-NMR spectra (Table 1), as well as the presence of acetyl carbonyl, lactam carbonyl and $\propto, \beta$ - unsaturated carbonyl peaks at 1750,1700 and $1660 \mathrm{~cm}^{-1}$ respectively; these carbonyl carbons give signals at 171.20, 171.92 and $184.45 \mathrm{ppm}$ in the ${ }^{13} \mathrm{C}$-NMR spectrum of compound II (Table 2). Again elemental analysis is consistent with the assigned structure for this compound. The base peak in the mass spectrum of compound II is the molecular ion peak at $\mathrm{m} / \mathrm{z} 447$.

The steroidal indole (III), obtained by reduction of compound I with sodium borohydride in ethanol, gives a positive Ehrlisch test [7] for indoles, and its UV spectrum is almost identical to that of 2-methylindole. The IR spectrum of compound III shows the presence of only one carbonyl group $(\mathrm{COOH})$ at $1710 \mathrm{~cm}^{-1}$. Its ${ }^{1} \mathrm{H}-$ NMR spectrum shows signals for five aromatic protons (Table 2) while the ${ }^{13} \mathrm{C}$-NMR spectrum gives signals for aromatic carbons whose chemical shifts are almost identical to those of 2methylindole [8], as well as a carboxyl carbonyl signal at $177.77 \mathrm{ppm}$ (Table 2). Its mass spectrum shows a base peak at $\mathrm{m} / \mathrm{z} 131$, which is observed in the fragmentation pattern of alkyl indoles [9], in addition to the molecular ion peak at m/z 409.

\section{ACKNOWLEDGEMENT}

The assistance of Dr. D. J. Maitland, School of Chemistry, and Prof. J. Smith, School of Pharmacy, University of Bradford U.K. with the running of NMR and Mass Spectra is gratefully acknowledged. Financial support for this work was provided by the Deans' Committee, University of Nairobi.

\section{REFERENCES}

[1] A. Hassner, M.J. Haddadin and P. Catsoulacos. J. Org. Chem. 31 (1966) 1363-1369.

[2] F.N. Kamau, I.O. Kibwage, G. Muriuki, A.N. Guantai, J. Hoogmartens, E. Roets, C. Govaerts, H. Chepkwony and R. Busson, East Cent. Afr. J. Pharm Sci. 5 (2001) 44-48. 
[3] F.N. Kamau, I.O. Kibwage, A.N. Guantai, G. Muriuki and R. Munenge. East Cent. Afr. J. Pharm. Sci. 6 (2003) 26-29.

[4] B. Witkop and J.B. Patrick. J. Am. Chem. Soc. 73 (1951) 2188-2189.

[5] J.D. Loudon and G. Tenant. Quart.Revs. (London). 18 (1964) 389-396.

[6] D.N. Kirk and M.P. Hartshorn. Elsevier, Amsterdam. 1968 p. 181.
[7] K.M. Acheson. "An Introduction to the Chemistry of Heterocyclic Compounds", Interscience Publishers Inc. New York 1960, p 131.

[8] R.G. Parker and J.D. Roberts. J. Org. Chem. 35 (1970) 996-998.

[9] M. Nakagawa and T. Hino, Tetrahedron 26 (1970) 4491-4493. 